\title{
3
}

\section{Practicing Care: Constructing SOCIAL RESPONSIBILITY THROUGH FEMINIST Care EThics HILLEL ARNOLD}

$\Omega$ Society of American Archivist's "Core Values of Archivists" articulates eleven values intended to "guide the practices and activities of archivists." The description of social responsibility — the last of these values and the focus of this essayis reproduced below in its entirety. I urge you to read it closely, as my interpretation of social responsibility will accentuate this definition's inherent vagueness:

Underlying all the professional activities of archivists is their responsibility to a variety of groups in society and to the public good. Most immediately, archivists serve the needs and interests of their employers and institutions. Yet the archival record is part of the cultural heritage of all members of society. Archivists with a clearly defined societal mission strive to meet these broader social responsibilities in their policies and procedures for selection, preservation, access, and use of the archival record. Archivists with a narrower mandate still contribute to individual and community memory for their specific constituencies, and in so doing improve the overall knowledge and appreciation of the past within society. ${ }^{1}$

This definition raises more questions about social responsibility than it answers. Who are these "groups in society"? What is the nature of our responsibility to them? What is the "public good"? Most of all, it leaves us asking about the application of social responsibility. How does it affect our daily work? Who does it apply to? Where does social responsibility begin and end?

Elsewhere, archival thinkers address social responsibility indirectly, focusing on 
values that social responsibility supports. For example, some use "accountability" as a synonym for social responsibility, even when writing from opposing viewpoints. ${ }^{2}$ Others conceptualize environmental sustainability as a "public good," explicitly linking it to social responsibility. ${ }^{3}$ Still others use the value-augmented with an understanding of the inequitable distribution of power in society and critical frameworks of race, class, and gender - to argue that social justice is a fundamental principle to which archivists should aspire. ${ }^{4}$

In short, the definition of social responsibility and the literature surrounding it offer conflicting guidance on how one might begin to implement it in practice. Because SAA's core values are intended to be aspirational rather than legally enforceable, their application is left to individual archivists. ${ }^{5}$ This absence of application matters. By failing to clearly articulate what social responsibility is and how we can become more socially responsible, I argue that we fail the most vulnerable among us-whether they are our colleagues, researchers, donors, or the subjects of records in our care-because we fail to understand and respond to their needs.

This essay combines the aspirational goal of social responsibility with the tactical framework of feminist care ethics. Feminist care ethics, which originates in the work of psychologist Carol Gilligan and philosopher Nel Noddings, ${ }^{6}$ argues that moral understanding must be grounded in specific people, relationships, and contexts. Ethical behavior, care ethicists argue, is not learned in the abstract, but through the activities and interactions of everyday human life. As a result, care ethics values lived experience, emotion, and the body as legitimate agents of moral knowledge. Fundamentally oriented toward practice, it insists that a sense of empathy for others be accompanied by actions that attempt to meet their needs. Last, oriented toward the marginalized, it prioritizes the needs of the already vulnerable in society over those in positions of power. $^{7}$

In my formulation of this argument, I am indebted to writings by technologists, librarians, and archivists, who have applied feminist care ethics to information work. ${ }^{8}$ Even though these writers do not explicitly mention social responsibility, the connections they make between care and their work led the way toward feminist care ethics as a productive framework to define and implement social responsibility. Specifically, I draw heavily on the work of Michelle Caswell and Marika Cifor, who use care ethics to argue for "radical empathy." When we choose to base archival work in empathy, even when experiences and circumstances inspire emotions of anger, fear, or disgust, we open up possibilities for reorienting and transforming archival practice. ${ }^{9}$ They identify four key archival relationships where such a reorientation might occur: the relationships between archivist and records creator; archivist and subject of records; archivist and user; and archivist and larger communities. This notion of empathy as an ethical choice, and its application to specific people and relationships, is a productive articulation of how social responsibility could be learned, taught, and enacted. 


\section{Constructing Social Responsibility}

To build the scaffolding for a reimagining of social responsibility, I map Caswell and Cifor's four key archival relationships onto Joan Tronto's four "ethical elements of care": attentiveness, responsibility, competence, and responsiveness. Tronto, a political scientist and feminist care ethicist, articulates an ethic of care that acknowledges intersectional power dynamics between caregivers and care-receivers, seeks to thwart the consolidation of power by elites, and builds value for care work that shares power effectively. ${ }^{10}$ Ethical care, she posits, begins by paying attention to those around us. Through this attentiveness, we are able to understand the needs of others. An awareness of these needs must then lead to an assumption of responsibility for meeting those needs, or the sense that one has a responsibility to provide assistance to those in need. Not all attempts to provide care are effective, and sometimes promises of care are made with no intention of fulfilling them, so the competence of caregivers is thus another crucial element of ethical care. Last, the effectiveness of care activity must be based on the response provided by the care-receiver. This responsiveness requires maintaining a balance between the needs of caregivers and care-receivers so that neither are abused or manipulated through their vulnerabilities. ${ }^{11}$

To demonstrate how these two frameworks might be brought into conversation with each other to rethink, learn, and improve our practice of social responsibility, I will pair one of Tronto's ethical elements with one of the four archival relationships defined by Caswell and Cifor. Although all four of Tronto's elements of care are relevant to each relationship, for clarity in each case I have chosen the element that best reveals the ethical dimensions of a particular relationship.

Situating social responsibility in the framework of care ethics means replacing our normative understanding of archival practice as one composed of functions such as appraisal, accessioning, preservation, arrangement and description, and access services with one that centers real relationships with "particular others" - real people with real needs with whom we form real emotional bonds - as the fundamental building blocks of archival work. ${ }^{12}$ It means thinking of archival work as care work. It requires us to truly know those others; to build a deep contextual understanding of the needs, competencies, and desires of these individuals rather than relying on our own good intentions. ${ }^{13}$ Out of these relationships grow mutual—but not necessarily symmetrical—responsibilities. This focus on relationships and responsibilities springs from an understanding of humans as fundamentally connected rather than self-sufficient, isolated beings. In this view, the severing of relationships results in the diminishment and disruption of the world, thus the maintenance of human relationships is a morally loaded activity. ${ }^{14}$

This approach does not result in easy answers, but instead forces us to ask sharper and harder questions about social responsibility. Who are the creators of the records in our archives, and what responsibilities do we have to protect these individuals and organizations or, conversely, to hold them accountable? Whose lives are represented in our holdings, and what responsibilities do we have toward the care of those individuals and the larger societal groups to which they belong? Who accesses the records in our 
custody, and what do they want and need from us? How can a commitment to meeting our responsibilities be turned outward from the practice of isolated individuals or institutions to concerted collective action that affects marginalized ethnic groups, the archival profession, our countries of origin, and even our planet?

\section{Attentiveness to Records Creators}

The path toward social responsibility begins with attentiveness, both to the needs of others as well as to the privilege these individuals or organizations hold in society. A socially responsible relationship between archivists and records creators must both prevent harm toward already marginalized populations and promote accountability for privileged individuals or organizations. This approach can have broad implications for processes of appraisal, description, and preservation. ${ }^{15}$

Archivists' attentiveness to the desires of wealthy or powerful records creators should not come at the expense of other records creators already in a position of vulnerability. At repositories that collect the records of society's elite, they may be allowed to drive the terms of deeds of gift, place access and use restrictions on collections, and specify "value-added" services or events (such as symposia or exhibitions) as conditions of their transfer of records. ${ }^{16}$ In an institutional records context, a powerful records creator may attempt to avoid accountability by circumventing records retention policies. The ongoing emotional labor of convincing these creators to cooperate with records retention schedules falls to archivists. ${ }^{17}$. Attentiveness to their relationships with records creators can help archivists correct existing collecting practices that view the acquisition of records as a market transaction. For archivists who work with institutional records, attentiveness can provide an ethical basis for the substantial labor involved in sustaining ongoing relationships with individuals, departments, and agencies to implement records transfers based on schedules or laws.

Attentiveness to the needs of others requires first attending to our own needs as archivists. ${ }^{18}$ It means honestly assessing whether or not we have the resources needed to arrange, describe, preserve, and make accessible records we acquire before we acquire them. It means having a firm grasp of the size and scope of our backlogs, so that we can ensure that the voices of marginalized records creators are not further silenced and, also, so that powerful voices are held accountable. Failure to do so makes archivists complicit in "privileged irresponsibility," or willful ignorance on the part of the privileged in society regarding the needs of others. ${ }^{19}$

This includes attention to inequities surrounding the distribution of labor. Not all care needs are equally met: the powerful generally determine the need for care as well as the appropriate response to it, while the marginalized and vulnerable perform and are directly impacted by the labor of care. For example, wealthy individuals are able to pay for domestic labor, child-care, and health-care workers for family members, while those without resources cannot afford to outsource that labor and often end up performing it for others. ${ }^{20}$ Archivists are often subject to these same power disparities in their 
work, struggling with a chronic lack of resourcing, a transient and underemployed workforce, and individuals in positions of authority who seek to operate outside the policies they themselves have created. These are all reasons why an ethical approach to social responsibility that acknowledges and seeks to address this distribution of power through an understanding of relationships and responsibilities is essential for archivists.

A strengthened understanding of social responsibility would help archivists resist taking on "legacy-care" for the powerful and ameliorate our complicity in the privileged irresponsibility of records creators who seek to write a particular version of their legacy into history either by placing their records in an archival repository or by preventing them from being transferred, preserved, and made accessible. At the same time, it might help us to better attend to the needs of marginalized records creators by considering their wishes regarding privacy, representation, and access when making appraisal, description, or preservation decisions. ${ }^{21}$

\section{Responsibility for Subjects of Records}

Archival theory and practice fail to substantially acknowledge the subjects of records. In many cases, even the very existence of these individuals and organizations is ignored. ${ }^{22}$ Care-based social responsibility can bridge this gap by insisting that archivists assume responsibility for the needs of the subjects of archival records. As in relationships with creators of records, archivists' ability to take responsibility for the needs of the subjects of records requires attention to power. Individuals in positions of power are adept at manipulating the perception of needs to their own advantage and often use legitimate care needs to distract from unethical activities. Social responsibility must, therefore, expose attempts to use care to reinforce positions of power and privilege. ${ }^{23}$

Archival relationships with subjects of records can and often do transcend time, even if archival functions of arrangement, description, access, and preservation of records are separated from the lives of the subjects of records in time or space. ${ }^{24}$ Thus, a practice of social responsibility in relationships with subjects of records must allow us to extend care-based social responsibility forward and backward in time. We can and must forge real relationships with both the dead who are subjects of records as well as with the not-yet-living who will become subjects as well. Such relationships with the absent undergird a practice of social responsibility just as much as do relationships with the living subjects of records.

As archivists, we should question our practices and standards for the description of records, which provide for representations of creators of records but treat information about the lives of the subjects these records document as an afterthought. ${ }^{25}$ Although recent trends in archival standards demonstrate more attentiveness to these individuals and organizations, our standards still do not take responsibility for providing spaces in which the voices of the subjects of records can be heard. ${ }^{26}$ Social responsibility must place an emphasis not just on the identification and robust description of subjects of records, but also on their agency, allowing them to speak from the identity and language of their choosing. ${ }^{27}$ 


\section{Responsiveness to Users of Records}

Responsiveness to our researchers, or soliciting their assessment of archival processes and basing future actions on that feedback, ${ }^{28}$ is an important antidote to the inequities that are often part of relationships between archivists and users of records. To achieve this responsiveness, we must both understand our researchers as vulnerable individuals and be alert to the possibilities of abuse in our own work. ${ }^{29}$

This iterative cycle of listening, taking appropriate action, and then evaluating the results of that action closely mirrors the methodology of human-centered design, which promotes the observation of user behavior followed by a series of rapid iterations to improve design and user testing of those changes. ${ }^{30}$ Although human-centered design practices have become more common in archives technology work, I argue that this methodology is more broadly applicable in archives, beyond interactions with technological interfaces. ${ }^{31}$ For example, a socially responsible approach to the archival enterprise might use human-centered design methodologies to develop and maintain standards for archival description. Reference services could be evaluated both comprehensively and singly by observing user behavior, making iterative changes to improve these services, and testing the results of these changes with researchers. ${ }^{32}$ Aspects of the physical environment, such as signage and room layout, could also be considered part of enacting social responsibility. ${ }^{33}$ An ongoing and intentional practice of building relationships with our users through these techniques could reframe archival processes, standards, and principles in more socially responsible ways.

Archivists may also address their social responsibility mandate by protecting the privacy of their users. This includes making systems choices that, at minimum, reduce the amount of information collected on researchers. More optimally, we should provide robust security and mechanisms by which researchers can delete their data at will. It also means pushing back on collection of personally identifying information in proprietary systems and rethinking our processes to separate data collection from provision of service to the greatest extent possible. ${ }^{34}$

\section{Competence in Larger Communities}

The elements outlined above_attentiveness, responsibility, and responsive-ness — are implemented in vain if a commitment to improve our practice over time does not accompany them. Our competence is, then, a key element of social responsibility, ensuring that we move past good intentions into the world of action, but also that we understand the limits of our ability to provide care. ${ }^{35}$ It is also a key element of an ethical relationship between archivists and their profession, one of the larger communities with which archivists are in relation.

By insisting that we must iteratively improve the quality of our actions, the value of competence asserts the primacy of the individual professional judgment of archivists over and above institutional mandates or professional codes of ethics. While a care- 
based understanding of social responsibility acknowledges that institutions that employ archivists often influence ethical action, it does not prioritize these organizations as moral arbiters, nor does it absolve archivists of individual ethical responsibility.

In addition to undermining attempts to offload ethical responsibility to institutions or professional codes of ethics, the recognition of competence as an ethical component of our work can help archivists more appropriately value labor across the archival enterprise. Archival funding, professional discourse, and attention focus disproportionately on anything that uses the word "digital," which means that functions like accessioning, some forms of preservation, and reference are often less visible, more poorly compensated, and undertheorized. Relative to the archival profession as a whole, men are overrepresented in these positions as well, adding a further dimension of inequality. ${ }^{36}$ These concerns intersect with recent scholarship on maintenance theory, which argues that the work of innovation is systematically privileged over the work of continuity and further that marginalized people perform maintenance work, ultimately leading to the devaluing of some human labor along lines of gender, race, and class. ${ }^{37}$

Social responsibility within the archival profession includes overhauling rewards structures to compensate, promote, and acknowledge all competently performed work, rather than privileging work described as "innovative." It also includes reimagining our staffing models so that we do not rely on part-time, unpaid, or temporary labor to fulfill ongoing operational needs and investing theoretical energy in archival functions like accessioning and preservation. It means valuing our maintainers.

Competence has particular implications for managers such as me. It is our social responsibility to ensure that positions are appropriately scoped so that new hires are neither expected to perform work far above their paygrades without adequate institutional support or resourcing, nor confined to dead-end roles with no opportunity for growth or learning. We must commit to providing ongoing learning opportunities and equitable promotion paths for our employees across archival functions. We must be willing to use our privilege to advocate for these things to resource allocators and to undercut that privilege by listening to and learning from junior employees.

Finally, valuing competence offers an alternative metric by which to measure archival practice. Increasingly, we evaluate our work so that resources can be effectively allocated, inefficiencies removed, and performance improved, but rarely is our work measured against a standard of care. ${ }^{38}$ And, even less often is meeting a standard of care considered a moral imperative, let alone a business obligation. Social responsibility can augment these metrics by articulating a level of care to be achieved in the context of a particular archival function.

\section{Learning by Doing}

In mapping ethical elements of care to the archival enterprise, I have sought to lay out ways in which care ethics can be used as a roadmap to guide archivists toward 
an increased sense and practice of social responsibility. In many cases, the work I advocate for is work that archivists are already doing. Yet it is often emotionally and psychologically exhausting work, seldom valued or even recognized. Recasting these seemingly mundane and inconsequential pieces of work as central to social responsibility lifts up these tasks and reconfigures them as points in a constellation of ethical practice. It helps us to keep doing the work and to keep trying to do the work better.

Although I argue that we must start with the local, the particular, and the small, our practice of care-based social responsibility can and must expand outward from our personal lives to our institutions, our local communities, our profession, and our world. ${ }^{39}$ In fact, care ethicists claim that moral lessons learned in private settings necessarily flow into public spaces and interactions. The acquisition of moral judgment developed in the course of that work moves naturally, they argue, toward efforts to restructure society and reconfigure relationships between the personal and the political on a larger scale. ${ }^{40}$

Because it requires attentiveness, the practice of care-based social responsibility is a critical tool for exposing asymmetrical power dynamics and inequitable relationships in society, requiring that we acknowledge ways in which race, gender, class, sexual orientation, or age coincide with the contours of social power. ${ }^{41}$ Because responsibility follows that awareness, our sense of obligation moves outward from the local and concrete to the broad and abstract. Along the way, we learn what kinds of actions are effective by attending to the responses they elicit. This growth of understanding and competence allows us to band together with other professionals, turning our individual actions into collective action.

Care-based social responsibility requires flexibility. We cannot expect that social responsibility will manifest consistently across individual or institutional contexts. Neither can we expect that social responsibility will remain static in the context of shifting relationships and power dynamics. It also takes persistence. Underlying all my arguments about social responsibility is the fundamental assumption that this value must be actively practiced. Merely searching for a concise and coherent definition will not get us closer to a more socially responsible archival profession. But a sustained commitment to engage with the challenges, ambiguities, and growth that come with an ethical practice might. ${ }^{42}$ A concrete sense of social responsibility will only be achieved once we actively acknowledge the real relationships that make up our practice, understand the responsibilities inherent in those relationships, and then act on them.

Which of our records creators have power, and which do not? How can we attempt to address those imbalances? What are the gaps in our collections, and why do they exist? Do they represent the voices of the powerful who are trying to escape accountability? Are they the voices of the marginalized being further silenced? How can we provide agency for records creators and subjects? Can we re-envision the process of standards maintenance as one that accommodates an ethic of care? What can we do to value the often transient and underpaid labor of new professionals who overwhelmingly do this work? What are the needs of our researchers, and how can we implement user-centered services and systems that adequately address them? How can we create 
research experiences that do not replicate structures of surveillance and oppression but instead offer broad, meaningful, and equitable access to records? What can we do to enable research that promotes accountability for the powerful and protection for the marginalized? And always, let us ask how we can improve. What are we doing wrong and why? What are the implications of our mistakes, and who is affected? How can we get better? And how can we share those lessons across the profession to build competence?

Social responsibility is not self-generating. Instead, it is learned through purposefully targeted listening, combined with an intent to both act in response to needs one has heard as well as to continually evaluate one's actions. Feminist care ethics offers us a scaffolding within which we can learn how to sense social responsibility, act on that ethical knowledge, and then measure the results of our actions. Social responsibility as an ethic of care offers us a way to teach social responsibility to others in the profession and a way to advocate for the value of our labor to those outside of the profession.

\section{Notes}

I would like to thank Maureen Callahan, Jarrett Drake, Ruth Kitchin Tillman, Mark Matienzo, Eira Tansey, and Chela Scott Weber for reviewing drafts of this essay and providing substantial feedback that shaped its content and structure. And, most of all, I would like to thank Azra Dawood, without whose sustained encouragement, guidance, and care, this piece would never have been written. Any errors or omissions are mine alone.

\footnotetext{
${ }^{1}$ Society of American Archivists, "Core Values of Archivists," May 2011, https://www2.archivists.org statements/saa-core-values-statement-and-code-of-ethics\#core_values. The origin of the core values statement is usually traced back to Mark A. Greene's 2009 presidential address ("The Power of Archives: Archivists' Values and Value in the Postmodern Age [with an introduction by Dennis Meissner"], American Archivist 72, no. 1 (2009): 13-41, doi:10.17723/aarc.72.1.k0322x0p38v44153), although it is worth noting that Greene does not discuss social responsibility in this speech. The core values, approved by SAA Council in 2011, are intended to be used in conjunction with SAA's "Code of Ethics for Archivists," which have a longer history stretching back to 1982, including several revisions. See Society of American Archivists, "Code of Ethics History"," http://www2.archivists.org/groups/committee-onethics-and-professional-conduct/code-of-ethics-history.
}

${ }^{2}$ See Mark A. Greene, "A Critique of Social Justice as an Archival Imperative: What Is It We're Doing That's All That Important?," American Archivist 76, no. 2 (2013): 302-34, doi:10.17723/ aarc.76.2.147441214663kw43; Randall C. Jimerson, "Archivists and Social Responsibility: A Response to Mark Greene", American Archivist 76, no. 2 (2013): 335-45, doi:10.17723/ aarc.76.2.2627p15350572t21.

${ }^{3}$ See Heidi N. Abbey, "The Green Archivist: A Primer for Adopting Affordable, Environmentally Sustainable, and Socially Responsible Archival Management Practices"," Archival Issues 34, no. 2 (2012), http://digital.library.wisc.edu/1793/72389; Todd Welch, "Green' Archivism: The Archival Response to Environmental Research", American Archivist 62, no. 1 (1999): 74-94, doi:10.17723/ aarc.62.1.b5083wmj61g73608; as well as more recent scholarship such as Eira Tansey, "Archival Adaptation to Climate Change," Sustainability: Science, Practice, and Policy 11, no. 2 (2015), doi:10.7945/ C2RC7N.

${ }^{4}$ See Ricardo L. Punzalan and Michelle Caswell, "Critical Directions for Archival Approaches to Social Justice", The Library Quarterly 86 no. 1 (2016): 25-42, doi:10.1086/684145; and Randall C. Jimerson, "Archives for All: Professional Responsibility and Social Justice"," American Archivist 70, no. 2 (2007): 252-81, doi:10.17723/aarc.70.2.5n20760751v643m7. It should also be noted that, although social 
responsibility has been used to justify the inclusion of social justice as a core archival value, it has also been used to argue against its inclusion. The foremost example is Mark Greene's 2013 article in American Archivist, "A Critique of Social Justice as an Archival Imperative: What Is It We're Doing That's All That Important?," which attempts to replace individual morality and obligation with institutional and professional obligations. "We serve our institutions, and some of our institutions serve the public" (326).

${ }^{5}$ Society of American Archivists, "Code of Ethics History."

${ }^{6}$ Carol Gilligan, In a Different Voice: Psychological Theory and Women's Development (Cambridge, MA: Harvard University Press, 1982); and Nel Noddings, Starting at Home: Caring and Social Policy (Berkeley: University of California Press, 2002).

7 "Internet Encyclopedia of Philosophy", s.v. "Care Ethics," by Maureen Sander-Staudt, http://www.iep. utm.edu/care-eth; Virginia Held, The Ethics of Care: Personal, Political, and Global (Oxford; New York: Oxford University Press, 2006), 11; or Joan C. Tronto, Moral Boundaries: A Political Argument for an Ethic of Care (New York: Routledge, 1993), 103, quoting earlier article by Tronto and Berenice Fisher.

${ }^{8}$ Stacie Williams, “All Labor Is Local," On Archivy (blog), November 13, 2016, https://medium.com/@ Wribrarian/all-labor-is-local-344963e33051, applies care ethics to the library profession generally, while Lisa Sloniowski, "Affective Labor, Resistance, and the Academic Librarian," Library Trends 64, no. 4 (2016), http://yorkspace.library.yorku.ca/xmlui/handle/10315/31500, discusses ways in which care ethics affect academic librarians. Bethany Nowviskie, "Capacity through Care" (blog), February 20, 2016, http://nowviskie.org/2016/capacity-through-care, looks at this subject through the lens of academia, while Amelia Abreu has written a series of articles on care ethics in the tech industry, for example, "Does Care Work Matter in the Tech industry? (No, but It Should.): Notes on Care Ethics, Designing, Building, and Maintaining Technologies"," On Archivy (blog), ), March 16, 2016, https://medium.com/ process-design-thinking-for-engineering-and/does-care-work-matter-in-the-tech-industry-no-but-itshould-32134874d5e6; "Towards an Ethic of Care"”," On Archivy (blog), June 27, 2016, https://medium. com/@ameliaabreu/towards-an-ethic-of-care-26769966feca (the first of a four-part series). See also work on affect and emotional labor in archives, for example Ann Cvetkovich', An Archive of Feelings: Trauma, Sexuality, and Lesbian Public Cultures (Durham, NC: Duke University Press, 2003); as well as Michele Caswell, Marika Cifor, and Mario H. Ramirez, “'To Suddenly Discover Yourself Existing': Uncovering the Impact of Community Archives", "American Archivist 79, no. 1 (2016): 56-81, doi:10.17723/03609081.79.1.56. Additionally, Anna St. Onge's introduction to a roundtable presentation at the 2016 Association of Canadian Archivists, "Already Enough Ghosts: The Invisibility of Emotional Labour in Archives," provides a number of examples of emotional labor in archival work.

${ }^{9}$ Michelle Caswell and Marika Cifor, "From Human Rights to Feminist Ethics: Radical Empathy in the Archives." Archivaria 81 (May 6, 2016): 23-43.

${ }^{10}$ Internet Encyclopedia of Philosophy, s.v. "Care Ethics."

${ }^{11}$ Tronto, Moral Boundaries, 127-40.

${ }^{12}$ The concept of "particular others" is proposed by Virginia Held in Feminist Morality: Transforming Culture, Society, and Politics (Chicago: University of Chicago Press, 1993), 57-58.

${ }^{13}$ See Virginia Held, The Ethics of Care: Personal, Political, and Global (Oxford; New York: Oxford University Press, 2006), 10-11; and Tronto, Moral Boundaries, 136.

${ }^{14}$ Held, The Ethics of Care, 13; Nel Noddings, "Caring", " in Justice and Care: Essential Readings in Feminist Ethics, ed. Virginia Held (Boulder, CO: Westview Press, 1995), 7-30.

${ }^{15}$ Caswell, and Cifor, "From Human Rights to Feminist Ethics," 34.

${ }^{16}$ Examples of these accommodations, which create additional layers of administrative and technical complexity that archivists must manage, are widespread. Examples of these accommodations, which create additional layers of administrative and technical complexity that archivists must manage, are usually documented in Conditions Governing Access notes for these collections. This does not take into account the scenario of purchased collections, which adds yet another layer of asymmetry between unequally resourced archival institutions. 
${ }^{17}$ Eira Tansey, "Institutional Silences and the Digital Dark Age", Issues \& Advocacy (blog), May 23, 2016, https://issuesandadvocacy.wordpress.com/2016/05/23/institutional-silences-and-the-digital-dark-age.

${ }^{18}$ Tronto, Moral Boundaries, 131

${ }^{19}$ Tronto, Moral Boundaries, 121.

${ }^{20}$ See Tronto, Moral Boundaries, 113-14 and 146.

${ }^{21}$ Caswell and Cifor, "From Human Rights to Feminist Ethics," 34.

${ }^{22}$ Caswell and Cifor, "From Human Rights to Feminist Ethics," 36.

${ }^{23}$ Tronto, Moral Boundaries, 140. For example, see the 2015 University of Oregon case in which concern for exposure of private student data was used as a distraction from the administration's antifaculty actions documented in the records. Lisa Peet, "Faculty Rallies to Support University of Oregon Archivist"," Library Journal, https://web.archive.org/web/20170112200739/http://lj.libraryjournal.com/2015/04/ industry-news/faculty-rallies-to-support-university-of-oregon-archivist/.

${ }^{24}$ Caswell and Cifor, "From Human Rights to Feminist Ethics," 33.

${ }^{25}$ Describing Archives: A Content Standard and International Standard for Archival Description (General) both include data elements for creators of records, but not for their subjects. This information may be included in a Scope and Content element, along with details of record format, context of creation, etc.

${ }^{26}$ See comments on implications of declaring the gender identities of agents in archival records in Technical Subcommittee on Describing Archives: A Content Standard (TS-DACS), "Records in Contexts (RiC) Comments"," December 7, 2016. https://docs.google.com/document/d/1XoQmrT-kdj5fCKNcg0umg hsWFORrKRf7rMsB4OsnY5o/edit.

${ }^{27}$ For examples of this kind of liberatory descriptive practice, see a discussion of A People's Archive of Police Violence in Cleveland and efforts to document Princeton University student activism in Jarrett M. Drake, "RadTech Meets RadArch: Towards a New Principle for Archives and Archival Description"," On Archivy (blog), April 6, 2016, https://medium.com/on-archivy/radtech-meets-radarch-towards-a-newprinciple-for-archives-and-archival-description-568f133e4325.

${ }^{28}$ For an example of such an approach, see Merrilee Proffitt, Jim Michalko, and Melissa Renspie, "Shaping the Library to the Life of the User: Adapting, Empowering, Partnering, Engaging" (Dublin, OH: OCLC Research, 2015), http://www.oclc.org/content/dam/research/publications/2015/oclcresearch-shapinglibrary-to-life-of-user-2015.pdf.

${ }^{29}$ Tronto, Moral Boundaries, 135.

${ }^{30}$ For examples of this approach, see Steve Krug, Don't Make Me Think!: A Common Sense Approach to Web Usability (Berkeley, CA: New Riders Pub., 2006) as well as Donald A. 'Norman, The Design of Everyday Things (New York: Basic Books, 2002).

${ }^{31}$ Richard Buchanan, "Human Dignity and Human Rights: Thoughts on the Principles of HumanCentered Design"," Design Issues 17, no. 3 (2001): 35-39, doi:10.1162/074793601750357178 and Godfrey, Krista. "Creating a Culture of Usability." Weave: Journal of Library User Experience 1, no. 3 (2015). doi:http://dx.doi.org/10.3998/weave.12535642.0001.301.

${ }^{32}$ For examples of approaches to human-centered design which incorporate services see Joe Marquez and Annie Downey, "Service Design: An Introduction to a Holistic Assessment Methodology of Library Services"," Weave: Journal of Library User Experience 1, no. 2 (2015), doi:http://dx.doi.org/10.3998/ weave.12535642.0001.201; and Courtney Greene McDonald and Association of College and Research Libraries, Putting the User First: 30 Strategies for Transforming Library Services (Chicago: Association of College and Research Libraries, 2014).

${ }^{33}$ Andy Priestner and Matt Borg, eds., User Experience in Libraries: Applying Ethnography and HumanCentred Design (Farnham, Surrey, England; Burlington, VT: Routledge, 2016); and Aaron Schmidt and Amanda Etches, Useful, Usable, Desirable: Applying User Experience Design to Your Library (Chicago, IL: American Library Association, 2014).

${ }^{34}$ See Angela Galvan, "Architecture of Authority", Angela Fixes Things (blog), December 5, 2016, https:// 
asgalvan.com/2016/12/05/architecture-of-authority, for a careful and devastating deconstruction of the relationship between information professionals and software vendors; and Bonnie Gordon, "ACRL/ NY Symposium on Money \& Power"," Bits \& Bytes (blog), http://blog.rockarch.org/?p=1646, for a perspective on the ways in which open source software can support patron privacy.

${ }^{35}$ Tronto, Moral Boundaries, 133-34.

${ }^{36}$ This phenomenon has been widely discussed in literature on libraries, including Eleta Exline, "Gender Composition and Salary Gaps in Association of Research Libraries (ARL) Institutions" (master's thesis, University of New Hampshire, 2014); Gabrielle Dean, "The Shock of the Familiar: Three Timelines about Gender and Technology in the Library," Digital Humanities Quarterly 9, no. 2 (2015); Melissa Lamont', "Gender, Technology, and Libraries", Information Technology \& Libraries 28 (September 2009): 137-42; and Deborah Hicks, "Technology, Gender, and Professional Identity", in Deborah Hicks, 'Technology and Professional Identity of Librarians: The Making of the Cybrarian, 128-47 (IGI Global, 2014). Although data from a survey conducted by SAA's Women's Archivist Roundtable were not available at the time of writing, I note that, according to the $2006 \mathrm{~A}^{*} \mathrm{CENSUS}$ conducted by SAA, "the majority of archivists" are employed by academic institutions and thus would be subject to the same structural dynamics articulated in the above literature. American Archivist 69, no. 2 (2006): 328.

${ }^{37}$ Andrew Russell, and Lee Vinsel, “Hail the Maintainers", 'Aeon, https://aeon.co/essays/innovation-isovervalued-maintenance-often-matters-more.

${ }^{38}$ For example, see the work of the SAA-ACRL/RBMS Joint Task Force on Public Services Metrics.

${ }^{39}$ See Chris Bourg, "Diversity, Inclusion, Social Justice and Libraries: Proposing a Framework," Feral Librarian (blog), April 16, 2016, https://chrisbourg.wordpress.com/2016/04/16/diversity-inclusionsocial-justice-and-libraries-proposing-a-framework, for an example of this "concentric circles" model.

${ }^{40}$ Tronto, Moral Boundaries, 119 and 175. Held, The Ethics of Care, 12-19; Held, Feminist Morality, 225; Fiona Robinson, Globalizing Care: Ethics, Feminist Theory, and International Relations (Boulder, CO: Westview Press, 1999), 165.

${ }^{41}$ Held, The Ethics of Care, 18; Tronto, Moral Boundaries, 172-80; and Robinson, Globalizing Care, 16465.

${ }^{42}$ Care ethics insists that morality not put into practice is useless. See Gilligan, In a Different Voice, 149; and Tronto, 108 Moral Boundaries, 124.

\section{About the Author}

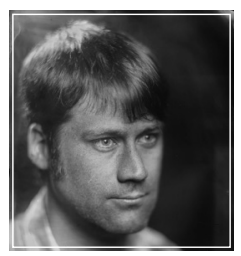

HILLEL ARNOLD is assistant director, head of Digital Programs at the Rockefeller Archive Center, where he leads the implementation of systems and processes facilitating broad and equitable access to and responsible preservation of archival records. He has served on the Society of American Archivists's Technical Subcommittee on Describing Archives: A Content Standard, Annual Meeting Task Force, and Encoded Archival Description Roundtable. Hillel has worked as an archivist at the Tamiment Library/Robert F. Wagner Labor Archives and the Woody Guthrie Archives. He holds an MA in history from New York University and an MLIS from the Long Island University's Palmer School. 